\title{
A Review of Applications of Linear Programming to Optimize Agricultural Solutions
}

\author{
Alanoud Alotaibi \\ Department of Information Systems, Imam Mohammad Ibn Saud Islamic University, Riyadh, Saudi Arabia. \\ Email: amdotibi@imamu.edu.sa

\section{Farrukh Nadeem} \\ Department of Information Systems, King Abdulaziz University, Jeddah, Saudi Arabia. \\ Email: fabdullatif@kau.edu.sa
}

Received: 29 December 2020; Accepted: 25 January 2021; Published: 08 April 2021

\begin{abstract}
Quantitative methods help farmers plan and make decisions. An apt example of these methods is the linear programming (LP) model. These methods acknowledge the importance of economizing on available resources among them being water supply, labor, and fertilizers. It is through this economizing that farmers maximize their profit. The significance of linear programming is to provide a solution to the existing real-world problems through the evaluation of existing resources and the provision of relevant solutions. This research studies various LP applications including feed mix, crop pattern and rotation plan, irrigation water, and product transformation; that have the main role to enhance various facets of the agriculture sector. The paper will be a review that will probe into the applications of the LP model and it will also highlight the various tools that are central to analyzing LP model results. The review will culminate in a discussion on the different approaches that help optimize agricultural solutions.
\end{abstract}

Index Terms: Linear programming, productivity, optimum, plan, crops pattern, land allocation, optimization.

\section{Introduction}

The agricultural sector is at the heart of contemporary societies as well as civilizations. The sector broadly encompasses livestock and the cultivation of plants. The agricultural sector makes an imperative role in meeting the growing food consumption demand across the world amidst the ever-increasing population. However, the increase in agricultural activities demands agricultural productivity and improved overall efficiency. Today the agriculture sector moves from agriculture1.0 to 4.0 [1], as shown in Figure1. The Figure explains how the agriculture sector was changed in a different era. In the first era, traditionally, the farmer used simple tools such as sickles, axes, pickaxes, shovels, etc. Agriculture productions depend on the workforce and animals to do agricultural activities. In this period, the production was very low because the people get tired and they cannot stand the hard work. Today, agriculture is transforming into Agriculture 4.0, which is called "Smart Farms." The emergence of many technologies like Big data, Artificial Intelligence, Remote Sensing, and Cloud Computing continue to improve agricultural efficiency. The efficiency manifests through a reduction in the water quantity used in irrigation, resource utilization, and overall environmental effects.

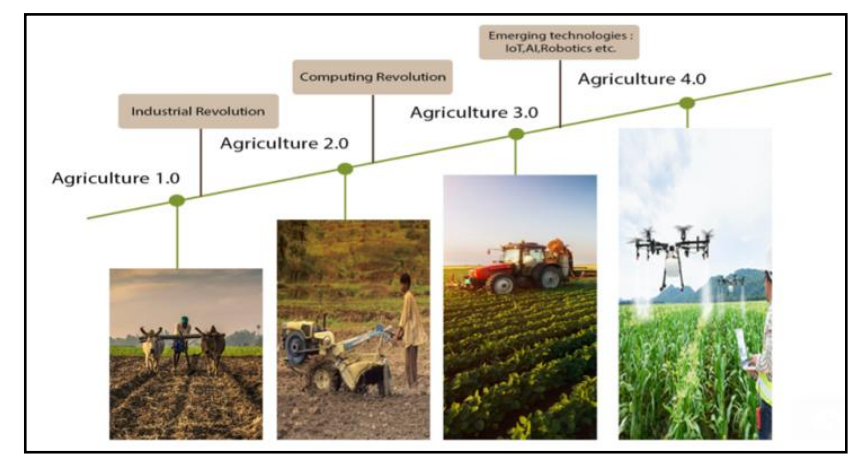

Fig.1. Agricultural era from 1.0 to 4.0 [1] 
Agriculture 4.0 is deemed as the next agricultural revolution due to a greater focus on precision agriculture and the Internet of Things (IoT) [2,3]. It is also an area where the farmer needs guidance about agricultural operations such as scheduling equipment for agricultural use, optimal allocation of economic, social, and developmental resources, optimizing the planting pattern, and agricultural land, etc. to maximize the incomes. For optimum agricultural production, the proper use of land, crop, soil, and water resources is necessary. Unfortunately, due to the intricacy of the agricultural sector, farmers have faced challenges in making the right decision regarding what to grow, which season, within available resources. The critical challenge is selecting the best among several activities. Subsequently, deciding for optimum selection of activities is a key issue.

Quantitative methods such as LP have a profound impact in addressing most problems faced by farmers in this era of agriculture 4.0. In this regard, Linear Programming was designed to help farmers in planning and making decisions about attaining and maximizing efficiency in production planning and resource allocation. The farmer needs to manage the available resources on the farm, such as labors, fertilizers, seeds, energy, etc. to maximize the profit. The previous researchers using LP in different aims, for example [4] helped farmers maximize profits based on proper chose the best crop at the right time and optimize land and water distributions for each of these crops. Also, [5] attempted to analyze the possibilities of increasing farm profitability by determining the optimum crop mix for crop cultivation under the following constraints: total area, intercropped area, and investment amount. Therefore, production maximization does not guarantee profit maximization. Therefore, it is apparent that linear programming methods have a significant role in optimizing the production planning of crops under a set of constraints set by farmers.

However, due to the lack of survey paper on LP's applications in agriculture's topics, this review will investigate the applications of the LP model in the agriculture sector in different areas. Below, we summarize our major objectives:

- We outline the various available tools that are central to analyzing the LP model's results and get useful insight that helps in making the right decisions.

- We demonstrate the six of the most common applications that have used LP to improve production, optimize resource allocations, and increase profits.

- We not only investigate the set of previous work but also present a summary of the insights behind each LP application and the model that was used to solve a certain problem.

- We particularly focus in this review on optimizing planting patterns, agricultural land, and resource allocation among others.

\section{Research Methods}

Researchers have been using LP to solve the main problems related to production, and resource allocations in the different applications as shown in figure 3. This paper aims to show the main objectives that discuss before through the following various sections. The first section will shed more light on the concept of linear programming and the subsequent section will expound on the different tools that make up the LP model. The next section will cover the applications of the linear programming model and this will be followed by a discussion on the main findings. The last section will be a conclusion that sums up the main points.

\section{Linear Programming Model}

The Linear Programming model is a technique that studies the maximum or minimum linear objective function under several restrictions to get optimum solutions. Initially, LP was applied to solve problems relating to the military and industrial sectors. Today, the model is widely applied to extensive financial, marketing, manufacturing and agricultural problems. In Finance, LP was used to identify capital budget, asset allocation, financial planning, etc. While marketing sector used LP to solve the problem related to marketing research and media selection. Also, LP was used to solve a problem related to the manufacturing sector for product mix problem, production, and scheduling. Similarly, the model was applied in the agricultural sector to optimize crop patterns as well as resource allocations (water, land, fertilizers, etc.).

LP is not a new concept because it was prevalent decades ago. It was developed before World War II by a Soviet mathematician A. N. Kolmogorov [6]. In 1945, Stigler developed the first application of LP in the field known today as "diet problems" [6]. With the significant advancement in this field, Waugh [7] introduced LP to determine the cheapest feeding and livestock rations combinations. In 1947, George D. Dantzig was the LP creator, released his first research works after World War II, just four years before Waugh's publication [8]. He worked on planning strategies after the World War for the US Air Force and formulated linear programming with inequalities to solve manufacturing and economic problems[6]. The problem he encountered was a large number of feasible solutions were presented because Dantzig formulated LP without adding an objective function[6]. Then he adds it to the structure of LP and then developed the simplex method to solve the problems. 
Before the linear programming model, farmers had to rely on traditional methods that involved trial and error and past experiments to solve any problem they faced, such as committing resources on available lands. Today, computing changes traditional methods by modeling the most real-world problems as linear programming problems and finding optimal solutions. Thus, farmers can use the LP model quickly and easily way to make the right decisions rather than traditional methods. For example,[9] used an LP model for allocating agriculture resources. They made a comparison between LP solutions and traditional solutions. They got a higher solution when they utilized the LP model. On the other hand, linear programming does not always guarantee optimal solutions, but there are feasible solutions. For example, [10] evolved an optimum land allocation plan to improve farm productivity under different winter crops using the simplex method of linear programming. He observed that the existing solution was the least profitable. Eventually, he got a different solution where he obtained Rs. 103340.82, which is 1.785 times greater than the previous net profit if the total land is 8.25 ha and lentils crop is planted there. The production's the planning of crops not only one application of LP, but there are various real-world problems related to different applications the can be formulated as LP such as feed mix problem, crop rotation plan, water, and land allocation, agriculture product transformation, and amount of fertilizers and so. These problems can be resolved through the LP model and this is why the model is crucial.

\section{A. Uses of LP model}

The model is applicable in identifying the optimal solution for selecting or combining agricultural projects to maximize income or reduce costs within available resources. It's an alternative method to the traditional way, which is "trial and error" that farmers were suffering from using it [11]. There are three main reasons for using the LP model to solve most problems that happen in the farms and these are:

1. Increasing profitability of small farmers' crop production and help them fulfill production requirements for food crops, and encourage them to use environmental resources[12].

2. Used to optimize profit, to examine whether or not profit increased after implementing the model [5], [10].

3. Many researchers [13]-[15] have been using the LP model's types, such as the fuzzy goal programming, to solve their problems in the farm field, where ambiguity and vagueness affect decision-making.

\section{B. Formulating LP model}

This study is premised on optimization by applying the LP model, which is a mathematical method of solving problems involving the quantity to be optimized (maximized or minimized) when certain constraints are added to that quantity. This section discusses the overview of the LP method. It is considered to be the most popular technique in operational research for models with objectives and constraints that are all linear functions. It consists of three basic components: decision variables that will determine the objective (goal) function, maximization or minimization, and constraints that the solution must satisfy. The objective function is a mathematical expression that combines the decision variables and their coefficients to achieve the optimum solution. The result of an LP problem represent by maximum or minimum value in the linear equation $f$ :

$$
f=c_{1} x_{1}+\cdots+c_{n} x_{n}
$$

The constraints represent limits in the model related to available resources. Note that it is possible to express the constraints as equations $(=)$ or inequalities $(\geq$ or $\leq$ ), but there are ambiguous problems when using strict inequalities such as">" or "<"[16].

In addition, the nonnegativity restrictions $X_{1} \geq 0, X_{2} \geq 0$ will add it with the constraints because the negative values of physical quantities are unattainable. The nonnegativity restrictions mean that we are always working in the first (or northeast) quadrant of a graph, as shown in Figure 2. The solution must be identified for linear inequalities (that is, find the values of variables $x_{i}$ that fulfill all the constraints simultaneously). Then substitute the values of these variables in the objective function $f$ to find a corner point that presents as an intersect of two lines. All corner points are related to the solution space. Solution space is a shaded area that satisfies all constraints and indicates that all points in this area are a candidate to be an optimal solution, as shown in figure 2. For example, in figure 2, the feasible solution set is represented by $\mathrm{x}_{\mathrm{i}}$ (blue lines). In contrast, the yellow line represents the objective function, which results in K's maximum value that satisfies all constraints at the corner of the solution space. All points in the dark yellow line are proposed to be optimal solutions because they give the highest cost for the problem. 


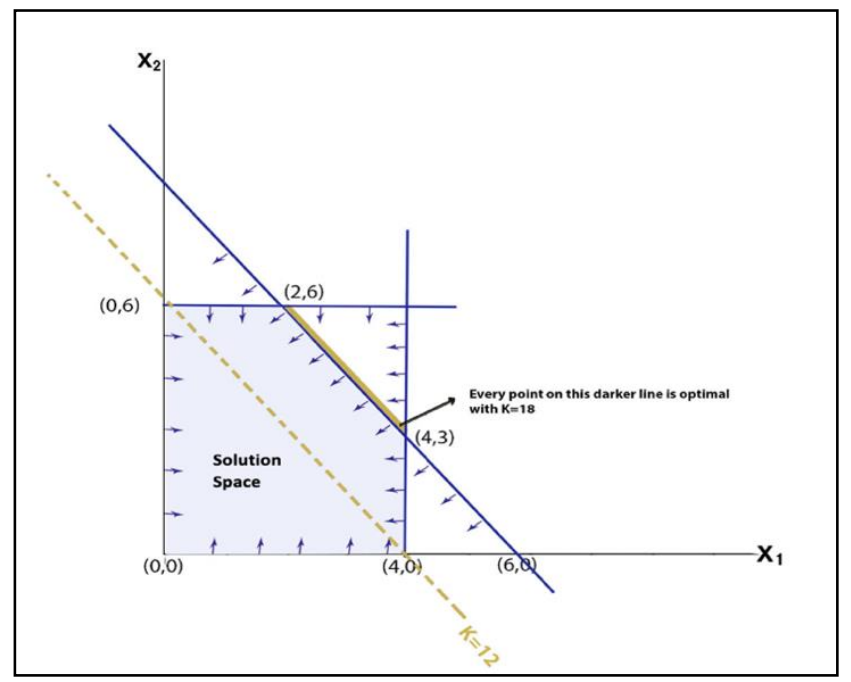

Fig.2. Calculating Optimal Solution of Linear Programming

During World War II, George D. Dantzig came up with an approach for solving linear programming. This was part of his research where he developed the simplex algorithm to solve problems in the real world. The simplex algorithm is the classical approach to solving linear programming optimization problems. It's an algorithm for finding a maximal or minimal value of function within a set of constraints. The challenge in achieving the initial feasible solution is challenging for LP models with $\geq$ or = type constraints because they lack original viability. In some cases, there is a need to combine LP with another approach for optimizing agriculture problems; for example, multi-goal programming (MGP), goal programming (GP), multi-objective programming (MOP), or weighted goal programming (WGP) can be working with LP to solve problems that have more than one goal. Also, the Fuzzy goal programming (FGP) approach can handle data with fuzzy objectives and constraints.

\section{Linear Programming Tools}

The LP model is made up of different tools that are essential in the optimization of linear programming models. These include software like LINDO, LINGO, and TORA can be mentioned. Below are some popular software used to optimize solutions in LP problems.

\section{Excel Solver}

Microsoft Excel has powerful functions as a quantitative analysis tool. It can provide a simple Solver function for identified feasible and optimum solutions. [6] explained the steps of how adding the Add-Ins solver function in MS Excel with a detailed description. The Solver is often referred to as the what-if analysis method [17]. Many researchers used MS-Excel to solve most optimization problems easily and quickly. For example, [17] provided a model for controlling uncertainty in agriculture income by Fuzzy Multi-objective Linear Programming (FMOLP) model that solves it very simply using the Solver tool in MS-Excel.

\section{AMPL}

AMPL (A Mathematical Programming Language) is used to solve mathematical models to optimize the model efficiently. It can solve models with many variables and constraints [18]. Other research[19] used AMPL to solve the vegetables' delivery problem to the point of sale within a short period. Also, [20] solved the problem of production and distribution of agricultural products by using AMPL with MINOS[20].

\section{Other Tools}

There are other tools used to solve the LP problem. For example,[21] used Python 2.7 and PyCharm as a code editor for creating an analytical program to maximize the revenue of the farm depending on the farmers' decisions during the plantation season. Other researchers [20,21] evaluated their solutions by using LINGO software. The major benefit of LINGO is its ability to formulate and analyzes big problems[18].

We can say that all previous tools can solve problems quickly and efficiently on formulating equations and solve problems. With linear programming models, these tools are essential in the optimization problems, and identify the optimal solutions helps to get valuable insight that enhances the decision-making process. 


\section{Solving Agricultural Problems by Applying Linear Programming}

In most agriculture planning problems, LP was used in different subjects, such as allocation of limited resources, including acreage of the land, availability of the water and labor, granted capital, etc. that aims to maximize the net income [24]. It evaluates the existing resources and then gives appropriate solutions based on quantitative analysis. In general, there are a wide variety of applications of LP in agriculture. Figure 3 illustrates most of the use of linear programming in agriculture. The following subsections describe the applications of LP in detail.

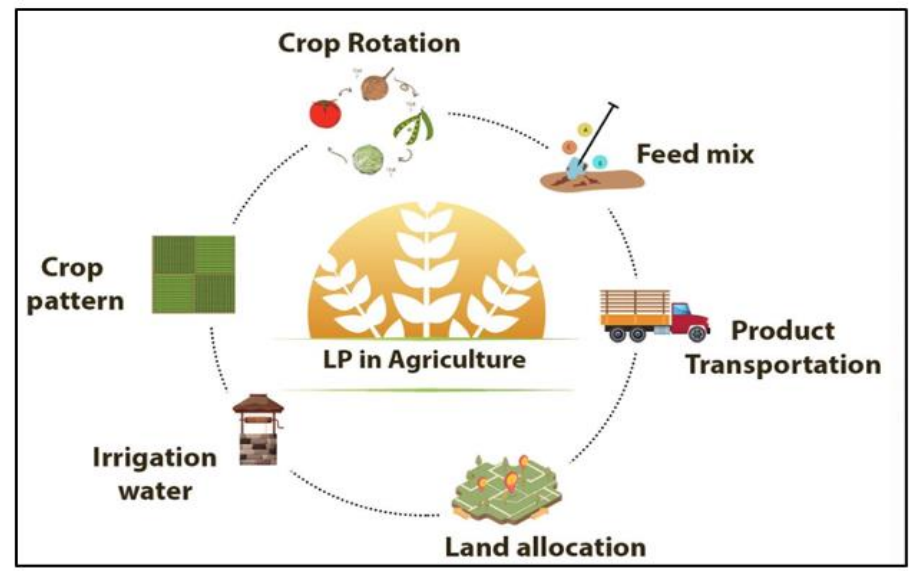

Fig.3. Applications of Linear Programming in Agriculture

\section{A. Feed Mix Problem}

The feed is one of the important variables in assessing the efficient production of livestock. The feed mix problem aims to identify the content of the feed mix by mixing in particular proportions of raw material with different contents [25]. The required quality properties and minimum costs should be determined to get the ideal feed mix. The LP model is the most common approach to solve the feed mix problem. Generally, the feed mix was used to increase the nutrient amount and weight gain, and livestock yield [26]. LP model formulates feed mixes to have a minimum cost to satisfy energy and nutritional requirements needs. The objective function of LP often focuses on minimizing the overall price of livestock feed, according to the limits of feed sources in each area or season. Many researchers used LP to optimize the feed mix cost based on livestock requirements[23, 24]. They suggested using other methods besides LP, such as GP, MOP, or MGP, to solve feed mix problems with more than one goal that should be optimized. The mixed-integer linear programming (MILP) model is another approach to help farmers decide the additional raw materials that were added to the mixture and achieve minimum costs among the mix's various components [25]. The worst standard deviation between all results of this model reached 0.294 . So, this method can give a consistent optimum result.

Diet-mixing of nutritional needs is also another area in which the model depends on multiple feed mixes to achieve an optimum feed mixture, taking into account the animals' nutritional requirements. [26] added the organic factor into the feed mix problem with two additional constraints: the availability of organic materials and organic food in the feed. These two constraints were added to solve on feed mix problem. The findings show that the ideal feed is selected to meet nutrient requirements and the organic ratio of feed and reduce total cost and organic raw material [27] build a model for minimizing costs and water content and seeking the optimum values for the best minimum water content values at various livestock levels to optimize the ration shelf life.

\section{B. Optimizing Crops Pattern}

Today due to an increasing population, land, and water resources become limited. But when providing irrigation facilities, the crop pattern in any agricultural region will increase. LP can help in determining the optimal crop pattern and production-planning pattern for food crops. This result will maximize the profits of the farmers' companies. [22] used the LP tool to represent the crop combinations' optimal value based on the proposed two approaches. The first approach is the land used for peas and wheat and livestock [22]. The second one is for mustard, grams, wheat, and pigs [22]. The results showed a 68 percent in farm 1; and 16.5 percent in farm 2; this means using LP affects returns that are rising in the farm. They concluded that livestock decreases production costs by providing natural fertilizers and improving soil fertility. [28] used the LP method, which is one way of optimizing the farms' productivity and providing a model for determining the appropriate crop combination to optimize benefit under a fixed limitation. The problem has benefited the farmer of 15,6499 Rs when plant peas instead of a mix of wheat, grape, and mustard.

The authors in [29] used LP to identify the optimum cropping pattern to give the region a maximum sales volume. The model is subject to various limitations, including water supply and the self-sufficiency of the crops, and land area 
restrictions for multiple crops during the different seasons of the year. The optimal outcome was compared with the existing one and resulted that the total net return after optimization reached 39,683 while it was 37,374 before the optimization. Crop mix is one of the planting schemes involving the simultaneous cultivation of more than one crop at the same time or season[30]. It is one of the problems that farmers can face who always ask themselves: which crops to plant when planted, and how much to plants. [30] proposed an LP-based model to maximize total revenue based on some restrictions such as cultivated land, available resources, and fixed budget.

\section{Crop Rotation Plan}

Crop rotation is a pattern where plants are planted on the same land [31]. Many constraints can affect the cropping plan, such as the weather and market. These constraints impact the planting during the seasons in a year and then affect the farm's productivity. LP identifies the appropriate plan to identify crop rotation patterns to achieve the optimum goal. In addition, LP is used to increase the volume of productivity, incomes, and effective use of existing resources. For example, [32] used LP to achieve the highest volume of productivity for the Al- Rasheed-Hamorabi farm in Baghdad by following the correct existing capital strategy use of available resources, including implementation of agricultural rotation to sustain soil fertility. He compared the income produced by the actual agricultural plan based on the previous information collected from 2015 to 2016 and derived the plan with LP's help. He found that net income was 4837145 thousand dinars in the actual plan, and increased to be 7930167.2 thousand dinars. The analysis is done on the same farm and seasons, and the farm gets a much higher income increased by 3093023 thousand dinars with fewer resources than the actual plan. The best plans, therefore, gave him higher revenue with limited resources.

In some cases, especially when the farm has more than one goal, the LP not enough alone to get a higher income, so a mix of LP with weighted goal programming (WGP) gives better results. Several researchers developed a model based on a mix of LP with weighted goal programming (WGP) to generate higher average income and lower costs per crop rotation and solve some problems [31, 32]. They mentioned the main issues that the model can handle, which are: crop strategy that is used need for extra resources such as labor, machines, fertilizer, etc., crop quantity, and fertilizer savings for crop rotation. This combination was tested and gave reliable results. The conclusion was that the combination of LP with weighted goal programming can optimize the crop rotation and enable the growth of farmers' income. Crop rotation is an essential application in farming, especially in organics one because it helps to preserve soil without using chemical fertilizers or even pesticides. [35] developed a model by using MILP to make a schedule for four-year crop rotation based on some restrictions such as irrigation pattern, crop yield, etc. to specify the market demand. The farm managers were satisfied with this model because the rotation can fulfill the business demand, and no one planting rules had been violated during the period.

\section{Land Allocation and Optimization}

Land allocation is the division of land between different types of crops to increase the total profit of the firm. In addition, it shows which product is more beneficial than others and how acreage will allocate to increase the profits. LP was used to determine land distribution to optimize different kinds of crops. Different methods can be used to identify the best allocation of the land, [24], used a Simplex method to determine land distribution to optimize different kinds of crops, which are Wheat, Rice, Pulses, Maize, and other crops. In the first period, 2409 acres of the land were used; after that, they used the simplex method to increase the profits when increasing the total area allocated to be 2752.56 acres. The work in [36] used the LP model for optimal allocation of the study area's 10 main crops. Simplex algorithms and Push-Pull algorithms provided the solution. They compared the results based on the number of iterations that the two algorithms take to make the right decision. They found that the second algorithm reached 20 iterations, while the first one was 11 iterations to get the right solution. The percentage of land distribution scheme for significant crops to increase the benefit in this study as follow: $21.49 \%$ for cotton, $13.47 \%$ for pulses, $5.45 \%$ for black gram, $14.8 \%$ for Jowar, $18.08 \%$ for Soya beans, $0.8 \%$ for sunflower, $6.7 \%$ for safflower, 39.5 for Gram, $15.97 \%$ for Green-gram, and no percent for wheat's land. With this distribution scheme, the total profit is Rs. 905217869, and the overall expenses of the seeds are Rs. 250481524.

The authors in [23] provided a comparison of using an LP model and integer linear programming models (ILP) to determine the appropriate land area for planting different kinds of Maple, Ash, Elm, Oak, and Bald cypress. The land area for planting has been determined using an LP model, whereas two integer linear programming models provide suitable species. The results indicated that the maple and bald cypresses were just two types that commercially available for agriculture production in the area, 151.3 and 355.3 ha, respectively. In most agriculture planning problems, there are unknown parameters that cannot be defined correctly in the constraints. To solve this issue, a fuzzy concept can be used. [14] used the FGP to identify the best allocation of cultivated land. They used the goal programming approach because several goals cannot be developed with the traditional method of linear programming, such as net income and water and labor supply. Furthermore, all these requirements are shaped as fuzzy. The result showed that crop production, net income, labor, and water requirements were fully met with most of the allocations' satisfaction. They conclude that the usefulness of the approach for land allocation for different crops. 


\section{E. Irrigation Water}

Irrigation water systems focus on scheduling the irrigation water among different farms from the cannel irrigation based on a specific time. It's essential to use methods and strategies for allocating water resources to sustain it and increase revenue - this application emerged later due to increased demand for water in the farms. A linear programming model is one method used to manage crop water every month. To get real income, the information related to the objective and constraints equations should be collected carefully by distributing questionnaires to be answered by the water carriers, irrigation supervisors, and farmers in the region. LP focuses on this area to find the optimum and correct utilization of water for irrigation in the agriculture sector. Besides, LP lead to an increase in the water productivity and net income of the farm. Various researchers work in this area and proved different results. For example,[37] made the scheduling for delivering water to multiple farm outlets with a minimum loss of water at a specific time that given to each farmer. The scheduling for water irrigation was based on the MILP model with two approaches: single period, and multi-period models. The single-period model sets a goal starting time, which will discharge once at the start of the irrigation period at the head of the channel. The multi-period model gave the user priority to schedule their actual start times for the corresponding irrigation period with target start times. These two schedules can help decide on the irrigation pattern to minimize the demand at the channel's head.

A study by [38] presented a plan for irrigation water distribution and an optimum planting pattern to optimize the net income and increase water productivity (WP). They showed that linear optimization with maximum benefit results gives the lowest water productivity. They used modeling to generate alternatives (MGA) technique to improve WP. MGA was used for enhancing the result of linear programming. They compared using the genetic algorithm and linear and integer programming. They found that the best water productivity was reached at a water deficit average of 30-35\% and $10 \%$ deviation when using MGA.

Another mathematical programming tool used to assess water resources is multi-objective fractional goal programming (MOFGP) and Fuzzy goal programming (FGP) methods. [39] used the multi-objective linear programming tool with fractional programming (FP) models to evolute the sustainability of the water resources based on two metrics which are "net income/water usage" and "labor/ water usage" to optimize the water usage and crop pattern in the rural farming. The findings indicate that FP models evaluated the sustainability metrics more than LP models. [15] used Fuzzy goal programming (FGP) to efficiently irrigate water management in various seasons in the planning year. They confirmed that FGP contributes to solving farm problems with an uncertain decision environment.

\section{F. Agriculture Product Transformation}

It's necessary to get the right decision in agriculture's product transportation. It should be optimizing the routing of agriculture products from source to destination centers to minimize total shipping costs or distances[40]. LP solves the production site's delivery problem to the distribution site with a short period and minimum fee. This particular case of LP, which is called a transportation problem. The transportation problem aims to deliver products to the distribution center with minimum distance or delivery cost based on supply and demand constraints. [19] using dynamic programming in the Dijkstra algorithm to deliver vegetables to the distribution center. By determining the shortest path from each supplier to the point of sale within a short period and decreasing vegetable compensation fees. They use AMPL software to model vegetable transportation with reasonable constraint optimization. The results were analyzed, and they found that 35 local vegetable distribution is appropriate for vegetable delivery. There is not much research that applies the classic LP model to solve this type of problem because it often relies on a particular kind of LP called the transportation models.

\section{Discussion}

From the qualitative data, it is apparent that the linear programming model is prevalent in operations research. It was first used by Waugh (1995) to optimize feed ration and determine the cheapest feeding and livestock rations. Usually, LP solved problems have one goal that aims to maximize or minimize a specific goal, usually costs, revenues, or net income. The simplex algorithm has been used to solve many real-world problems. It's the classical approach to solving linear programming optimization problems for finding a maximal or minimal value of function within a set of constraints. Several researchers found that LP with a Simplex method helps to get an optimum land allocation plan [10], [24], [36]. They found that it improved farm productivity and increased the profit when the total allocated area was increased.

Mixed-Integer Linear Programming model also another approach was used in the feed mix, crop rotation plan, and planning and scheduling the irrigation water[25], [35], [37]. This method can give a consistent optimum result, and the farm managers were satisfied with this model. On the other hand, Integer linear programming models can determine the optimum land area for growing different crops. A comparison was made between LP and ILP that give insight into which crop will grow in the proper land area [23].

In some cases, in the agriculture sector, the problems are defined with multi goals. So LP has a shortcoming in optimizing solutions with multi goals problem[34]. Other mathematical programming approaches that are utilized for 
optimizing agriculture problems with LP include GP, MGP, WGP, or MOP to solve problems with more than one goal. These approaches were used besides LP to get valuable results[23, 24, 25]. For example; The benefits of combining LP with WGP are that LP can help in minimizing or maximizing the objectives, while WGP simultaneously meets all LP sub-model objectives [34]. This combination was tested and gave reliable results [31, 32]. Also, the Fuzzy goal programming (FGP) tool can handle data with fuzzy objectives and constraints. FGP methods can contribute to solving farm problems with an uncertain decision environment. GP is also used to optimize crop production plan, feed mix, and irrigation schedule and planning.

All applications of LP were discussed to solve the problems in specific regions and identify the optimum feasible solution under several restrictions. Table 1 below summarizes these applications in a different area and show how LP contributed to solving the problem in different studies. In addition, Table 2 shows the objectives of using the LP model based on the previous researches and the software were used to achieve their goals.

Table 1. Overview of 20 studies with different applications of LP

\begin{tabular}{|c|c|c|c|c|c|}
\hline Study & $\begin{array}{l}\text { Application } \\
\text { areas }\end{array}$ & Problem targeted & Model & Contribution & Outcome \\
\hline$[8,22,34]$ & $\begin{array}{l}\text { Land allocation } \\
\text { and } \\
\text { optimization }\end{array}$ & $\begin{array}{l}\text { No optimal land } \\
\text { distribution to improve } \\
\text { cropping }\end{array}$ & $\begin{array}{l}\text { Simplex } \\
\text { method } \\
\text { of LP }\end{array}$ & $\begin{array}{l}\text { Evolved an optimum land } \\
\text { allocation plan to improve farm } \\
\text { productivity under different } \\
\text { crops. }\end{array}$ & $\begin{array}{l}\text { Increase the profits when the total } \\
\text { allocated area is increase. }\end{array}$ \\
\hline [27] & $\begin{array}{l}\text { Feed } \\
\text { problem }\end{array}$ & $\begin{array}{l}\text { There are an increase in } \\
\text { the expense and water } \\
\text { content for ruminant } \\
\text { ration formulation }\end{array}$ & LP & $\begin{array}{l}\text { Optimize costs in feed mix } \\
\text { problems based on livestock } \\
\text { requirements. }\end{array}$ & $\begin{array}{l}\text { Increasing the nutrient amount, } \\
\text { weight gain, and livestock yield. } \\
\text { They suggested using other methods } \\
\text { besides LP such as GP, MGP, or } \\
\text { MOP. }\end{array}$ \\
\hline [26] & $\begin{array}{l}\text { Feed } \quad \text { Mix } \\
\text { problem }\end{array}$ & $\begin{array}{l}\text { The organic raw } \\
\text { materials are high cost }\end{array}$ & LP & $\begin{array}{l}\text { Add organic factor into the feed } \\
\text { mix problem with two } \\
\text { additional constraints to reduce } \\
\text { the costs. }\end{array}$ & $\begin{array}{l}\text { Meeting nutrient requirements and } \\
\text { the organic ratio of feed and reduce } \\
\text { total cost and organic raw material. }\end{array}$ \\
\hline $\begin{array}{l}{[20, \quad 26,} \\
27,28]\end{array}$ & $\begin{array}{l}\text { Optimizing } \\
\text { Crop Pattern }\end{array}$ & $\begin{array}{l}\text { The farmers faced the } \\
\text { problem of determining: } \\
\text { what to plant? how to } \\
\text { plant? and when? to get } \\
\text { maximum profitability. }\end{array}$ & LP & $\begin{array}{l}\text { Optimize crop patterns by } \\
\text { maximizing crop yield. } \\
\text { Appropriate crop combinations } \\
\text { are also determined. }\end{array}$ & $\begin{array}{l}\text { The net returns on the farm were rise } \\
\text { after optimization. } \\
\text { Livestock decreased production costs } \\
\text { by providing natural fertilizers and } \\
\text { improving soil fertility. }\end{array}$ \\
\hline$[32]$ & $\begin{array}{l}\text { Crop rotation } \\
\text { plan }\end{array}$ & $\begin{array}{l}\text { How to effectively } \\
\text { utilize available } \\
\text { resources and increase } \\
\text { the income of the } \\
\text { Hamorabi Farm in } \\
\text { Baghdad. }\end{array}$ & LP & $\begin{array}{l}\text { Increasing the productivity of } \\
\text { the farm and income through } \\
\text { implementing crop rotation. }\end{array}$ & $\begin{array}{l}\text { It provides a higher revenue with } \\
\text { limited resources. } \\
\text { Agricultural rotation can help to } \\
\text { sustain soil fertility. }\end{array}$ \\
\hline$[31,32]$ & $\begin{array}{l}\text { Crop rotation } \\
\text { plan }\end{array}$ & $\begin{array}{l}\text { How to minimize } \\
\text { multiple costs of } \\
\text { production on farms. }\end{array}$ & $\begin{array}{l}\text { LP and } \\
\text { WGP }\end{array}$ & $\begin{array}{l}\text { Optimizing the crop rotation } \\
\text { and enable the growth of the } \\
\text { income of farmers. }\end{array}$ & $\begin{array}{l}\text { Generate higher average income and } \\
\text { lower costs per crop rotation. } \\
\text { This combination of models was } \\
\text { tested and gave reliable results. }\end{array}$ \\
\hline [25] & $\begin{array}{l}\text { Feed } \\
\text { problem }\end{array}$ & $\begin{array}{l}\text { What materials are to be } \\
\text { used in the mixture and } \\
\text { how much percent? }\end{array}$ & MILP & $\begin{array}{l}\text { Minimizing the costs of the } \\
\text { mixture in the feed mix } \\
\text { problem. }\end{array}$ & $\begin{array}{l}\text { The number of optimal solutions } \\
\text { decreased when increasing the } \\
\text { number of additional resources in the } \\
\text { mixture. } \\
\text { 0.294. the worst standard deviation } \\
\text { was reached. So, this model can give } \\
\text { a consistent optimum result }\end{array}$ \\
\hline [35] & $\begin{array}{l}\text { Crop rotation } \\
\text { plan }\end{array}$ & $\begin{array}{l}\text { How farmers can } \\
\text { determine a crop rotation } \\
\text { schedule based on } \\
\text { several requirements. }\end{array}$ & MILP & $\begin{array}{l}\text { Making a schedule for four- } \\
\text { year crop rotation based on } \\
\text { some restrictions. }\end{array}$ & $\begin{array}{l}\text { Crop rotation can fulfill the business } \\
\text { demand, and no one planting rules } \\
\text { had been violated during the period. } \\
\text { Farm managers were satisfied with } \\
\text { this model. }\end{array}$ \\
\hline [37] & Irrigation water & $\begin{array}{l}\text { Hard to manage the } \\
\text { work between farms } \\
\text { especially at the start of } \\
\text { irrigation periods. }\end{array}$ & MILP & $\begin{array}{l}\text { Formulating a model for } \\
\text { delivering water to multiple } \\
\text { farm outlets with a minimum } \\
\text { loss of water at a specific time } \\
\text { that is given to each farmer. }\end{array}$ & $\begin{array}{l}\text { Decide on the irrigation pattern and } \\
\text { make a schedule to minimize the } \\
\text { demand at the head of the channel. }\end{array}$ \\
\hline [23] & $\begin{array}{l}\text { Land allocation } \\
\text { and } \\
\text { optimization }\end{array}$ & $\begin{array}{l}\text { There are not many } \\
\text { studies relating to the } \\
\text { economics of forest } \\
\text { plantation. }\end{array}$ & ILP & $\begin{array}{l}\text { Determining the appropriate } \\
\text { land area for planting different } \\
\text { kinds of crops, and which crop } \\
\text { more profitable for plantation. }\end{array}$ & $\begin{array}{l}\text { The comparison made between LP } \\
\text { and ILP gives insight into which } \\
\text { crop will plant in the appropriate } \\
\text { land area. }\end{array}$ \\
\hline
\end{tabular}




\begin{tabular}{|c|c|c|c|c|c|}
\hline $\begin{array}{l}{[11, \quad 21,} \\
13]\end{array}$ & $\begin{array}{l}\text { Crops Pattern, } \\
\text { Irrigation water, } \\
\text { and Land } \\
\text { allocation and } \\
\text { optimization }\end{array}$ & $\begin{array}{lrr}\text { How to handle } & \text { many } \\
\text { factors } & \text { affect } & \text { the } \\
\text { planting? } & & \end{array}$ & FGP & $\begin{array}{l}\text { Optimum allocation of } \\
\text { cultivated land. } \\
\text { Efficient irrigation water } \\
\text { management. } \\
\text { Make a different effect on the } \\
\text { performance of the cropping } \\
\text { pattern. }\end{array}$ & $\begin{array}{l}\text { All goals have different effects on } \\
\text { the performance of the cropping } \\
\text { pattern on the farm. } \\
\text { These methods can handle fuzzy } \\
\text { objectives and constraints with } \\
\text { multiple goals that can't be } \\
\text { developed with the traditional LP's } \\
\text { approach. }\end{array}$ \\
\hline [39] & Irrigation water & $\begin{array}{l}\text { There are complex } \\
\text { criteria when planning } \\
\text { cropping patterns related } \\
\text { to social and economic } \\
\text { factors. }\end{array}$ & MOFGP & $\begin{array}{l}\text { Evolute the sustainability of } \\
\text { water resources based on } \\
\text { different metrics. }\end{array}$ & $\begin{array}{l}\text { Optimize the water usage and crop } \\
\text { pattern in farming. } \\
\text { The findings indicate that FP models } \\
\text { evaluated the sustainability metrics } \\
\text { more than the LP model. }\end{array}$ \\
\hline
\end{tabular}

Table 2. Objectives formulated in the LP model of 20 studies [ $\uparrow$ Maximization, $\downarrow$ Minimization]

\begin{tabular}{|c|c|c|c|}
\hline Categories & Objectives & Software Used & Authors \\
\hline $\begin{array}{l}\text { Optimum land utilization of } \\
\text { food crops }\end{array}$ & $\begin{array}{l}\uparrow: \text { Agriculture production, } \\
\text { Net Profit, Net Present } \\
\text { Value (NPV) }\end{array}$ & LINGO software & {$[12,21,22,34]$} \\
\hline Optimal feed formulation & $\downarrow$ : Cost of mixing the feeds. & $\begin{array}{l}\text { CPLEX Studio IDE, TORA } \\
\text { software }\end{array}$ & {$[23,24,25]$} \\
\hline Optimal crop combination & $\begin{array}{l}\uparrow: \text { Profit, Revenue, Net } \\
\text { returns. }\end{array}$ & $\begin{array}{l}\text { LINGO, } \quad \text { MS } \quad \text { Office } \\
\text { Excel, LINDO software }\end{array}$ & {$[11,20,26,27,27]$} \\
\hline Optimal crop rotation & $\begin{array}{l}\uparrow: \text { Total net income } \\
\downarrow: \text { Costs per crop rotation }\end{array}$ & $\begin{array}{l}\text { MS Office Excel, Xpress } \\
\text { optimizer software }\end{array}$ & {$[30,31,33]$} \\
\hline $\begin{array}{l}\text { Economic distribution of } \\
\text { crop water per month. }\end{array}$ & $\begin{array}{l}\uparrow: \text { Net profit, Water } \\
\text { productivity. } \\
\downarrow: \text { Minimize the demand at } \\
\text { the head of the channel. }\end{array}$ & LINDO software & {$[13,35,36,37]$} \\
\hline
\end{tabular}

\section{Conclusion and Future work}

The paper has comprehensively covered the main objectives of this research related to LP and how it can be particularly useful in optimizing problems in the agriculture sector. LP is often applicable whenever the main goal is attaining efficiency. This is helpful for farmers because it helps farmers in resource allocation and decision making instead of using trial and error. Due to the lack of survey paper on LP's applications in agriculture's topics, this review investigated the applications of the LP model in the agriculture sector in different areas. Based on previous studies, there are three main reasons for using the LP model to solve most farms' problems. One of them is to increase the profitability of small farmers' crop production, help them fulfill production requirements for food crops, and encourage them to use environmental resources. Most studies proved the usefulness of using LP in solving real-world problems and provided reliable results. LP models can optimize the farm's net incomes and productivity under the available resources such as cultivated acreage, labor, fertilizers, seeds, water supply, energy, etc. One of the techniques used to analyze linear programming problems is a Simplex algorithm to locate a maximal or minimal value within a variety of restrictions. However, LP has a shortcoming in optimizing solutions with multi goals problem. Thus, other mathematical programming approaches utilized for optimizing agriculture problems with LP include GP, WGP, MGP, or MOP to solve problems with more than one goal. Due to the agriculture sector's complexity, farmers have faced challenges in making the right decision regarding what to grow, which season, within available resources. The critical challenge is selecting the best among several activities. LP tools have powerful functions as a quantitative analysis tool that can quickly solve LP to optimize the profit depending on available resources. This review investigates the applications of the LP model in the agriculture sector in different areas. It describes the results of using different approaches to resolve common efficiency issues in the realm of agriculture.

In future work, a deep analysis of other applications of LP and make a comparison between different models, and then identify the advantages and disadvantages of each model was used.

\section{References}

[1] Z. Zhai, J. F. Martínez, V. Beltran, and N. L. Martínez, "Decision support systems for agriculture 4.0: Survey and challenges," Comput. Electron. Agric., vol. 170, pp. 1-16, 2020.

[2] K. R, A. Kashyap K, and K. Kumar T G, "Automated Agricultural FieldAnalysis and Monitoring System Using IOT,” Int. J. Inf. Eng. Electron. Bus., vol. 10, no. 2, pp. 17-24, 2018.

[3] K. Anil Kumar and A. D, "An Internet of Thing based Agribot (IOT- Agribot) for Precision Agriculture and Farm Monitoring," Int. J. Educ. Manag. Eng., vol. 10, no. 4, pp. 33-39, 2020.

[4] A. Varma, A. S. Nath, and V. Regikumar, "An agricultural resources optimization model," 2012 Annu. IEEE India Conf. INDICON 2012, pp. 1278-1283, 2012.

[5] P. K. Muhammed Jaslam, B. Joseph, T. Paul Lazarus, and T. Rakhi, "Determination of optimum crop mix for crop cultivation in Kerala homesteads," Indian J. Agric. Res., vol. 52, no. 1, pp. 22-27, 2018. 
[6] B. Render, R. M. Stair, and M. E. Hanna, Quantitative Analysis For Management, 11TH EDITI. PEARSON, 2012.

[7] F. Waugh, "The Minimum Cost Diary Feed," J. Farm Econ., vol. 33, no. 3, pp. 299-310, 1951.

[8] G. B.Dantzig, Linear Programming and Extensions. NJ.: Princeton, 1963.

[9] M. Felix and M. Judith, "A farm resource allocation problem: case study of small scale commercial farmers in Zimbabwe," $J$. Sustain. Dev. Africa, vol. 12, no. 2, pp. 315-20, 2010.

[10] A. Upadhyaya, "Application of optimization techniques for crop planning to improve farm productivity of ICAR-RCER, Patna, India," J. AgriSearch, vol. 4, no. 1, pp. 68-70, 2017.

[11] K. C. Igwe and C. E. Onyenweaku, "A Linear Programming Approach to Food Crops and Livestock Enterprises Planning in Aba Agricultural Zone of Abia State, Nigeria," Am. J. Exp. Agric., vol. 3, no. 2, pp. 412-431, 2013.

[12] M. T. Mellaku, T. W. Reynolds, and T. Woldeamanuel, "Linear programming-based cropland allocation to enhance performance of smallholder crop production: A pilot study in Abaro Kebele, Ethiopia," Resour. J., vol. 7, no. 4, pp. 1-15, 2018.

[13] R. Joolaie, A. Abedi Sarvestani, F. Taheri, S. Van Passel, and H. Azadi, "Sustainable cropping pattern in North Iran: application of fuzzy goal programming,” Environ. Dev. Sustain., vol. 19, no. 6, pp. 2199-2216, 2017.

[14] D. K. Sharma, R. K. Jana, and A. Gaur, "Fuzzy goal programming for agricultural land allocation problems," Yugosl. J. Oper. Res., vol. 17, no. 1, pp. 31-42, 2007.

[15] B. B. Pal, S. B. Goswami, S. Sen, and D. Banerjee, "Using fuzzy goal programming for long-term water resource allocation planning in agricultural system: A case study,” Commun. Comput. Inf. Sci., vol. 283, no. 1, pp. 170-184, 2012.

[16] H. A. Taha, "Modeling with Linear Programming," in Operations Research: An Introduction, 8th Editio., USA: Pearson Education, 1972, pp. 13-14.

[17] P. L. Kumari, G. K. Reddy, and T. G. Krishna, "Optimum Allocation of Agricultural Land to the Vegetable Crops under Uncertain Profits using Fuzzy Multiobjective Linear Programming,” J. Agric. Vet. Sci., vol. 7, no. 12, pp. 19-28, 2014.

[18] M. Heydari, F. Othman, K. Qaderi, M. Noori, and A. S. Parsa, "Introduction to linear programming as a popular tool in optimal reservoir operation, a review," Adv. Environ. Biol., vol. 9, no. 3, pp. 906-917, 2015.

[19] T. Wang, B. Wan, C. Xiao, and Y. Feng, "The linear Programming Model of Vegetables Transport Scheme Design," in International Conference on Modelling, Simulation and Applied Mathematics (MSAM 2015), 2015, pp. $282-284$.

[20] M. K. Islam, M. M. Alam, M. F. Uddin, and G. M. Faruque, "Coordination and Profit Optimization by Producer-Distributor System of Agricultural Products in Bangladesh,” Am. J. Appl. Math., vol. 8, no. 1, pp. 22-28, 2020.

[21] J. Romero and K. Smith, "Crop profit optimization for farmers," in IEEE Systems and Information Engineering Design Symposium(SIEDS 2016), 2016, pp. 289-291.

[22] M. Bhatia and A. Rana, "A mathematical approach to optimize crop allocation - A linear programming model," Int. J. Des. Nat. Ecodynamics, vol. 15, no. 2, pp. 245-252, 2020.

[23] Z. Mohammadi, S. M. Limaei, and T. R. Shahraji, "Linear programming approach for optimal forest plantation," J. For. Res., vol. 28, no. 2, pp. 299-307, 2017.

[24] N. A. Sofi, A. Ahmed, M. Ahmad, and B. A. Bhat, "Decision Making in Agriculture: A Linear Programming Approach," Int. J. Mod. Math. Sci., vol. 13, no. 2, pp. 160-169, 2015.

[25] M. A. Şahman, A. A. Altun, and A. O. Dündar, "A new MILP model proposal in feed formulation and using a hybrid-linear binary PSO (H-LBP) approach for alternative solutions," Neural Comput. Appl., vol. 29, no. 2, pp. 537-552, 2018.

[26] N. N. Ai Thy, J. Buddhakulsomsiri, and P. Parthanadee, "A Mathematical Model for Optimizing Organic Feed Mix Problem," in IEEE 7th International Conference on Industrial Engineering and Applications, ICIEA 2020, 2020, pp. 570-573.

[27] P. Saxena and N. Khanna, "Formulation and Computation of Animal Feed Mix: Optimization by Combination of Mathematical Programming," Adv. Intell. Syst. Comput., vol. 1, pp. 621-629, 2015.

[28] M. Bhatia and G. M. J. Bhat, "Linear Programming Approach- Application in Agriculture," J. Emerg. Technol. Innov. Res., vol. 6, no. 5, pp. 155-157, 2020.

[29] S. Osama, M. Elkholy, and R. M. Kansoh, "Optimization of the cropping pattern in Egypt," Alexandria Eng. J., vol. 56, no. 4, pp. 557-566, 2017.

[30] N. H. Mohamad and F. Said, "A mathematical programming approach to crop mix problem," African J. Agric. Res., vol. 6, no. 1, pp. 191-197, 2011.

[31] J. Dury, N. Schaller, F. Garcia, A. Reynaud, and J. E. Bergez, "Models to support cropping plan and crop rotation decisions. A review," Agron. Sustain. Dev., vol. 32, no. 2, pp. 567-580, 2012.

[32] R. S. M. Al-Nassr, "The Optimal Crop Rotation Of AL-RASHEED District Farms Using Linear Programming Technique," J. Agric. Sci., vol. 50, pp. 113-127, 2019.

[33] J. Prisenk and J. Turk, "A multi-goal mathematical approach for the optimization of crop lanning on organic farms: A slovenian case study," Pakistan J. Agric. Sci., vol. 52, no. 4, pp. 971-979, 2015.

[34] J. Prišenk, J. Turk, Č. Rozman, A. Borec, M. Zrakić, and K. Pažek, "Advantages of combining linear programming and weighted goal programming for agriculture application,” Oper. Res., vol. 14, no. 2, pp. 253-260, 2014.

[35] R. J. Forrester and M. Rodriguez, "An Integer Programming Approach to Crop Rotation Planning at an Organic Farm," UMAP J., vol. 38, no. 4, pp. 5-25, 2018, [Online]. Available: http://www.comap.com/product/?idx=1617.

[36] M. O. Wankhade and H. S. Lunge, "Allocation of Agricultural Land to The Major Crops of Saline Track By Linear Programming Approach: A Case Study,” Int. J. Scintific Technol. Res., vol. 1, no. 9, pp. 21-25, 2012.

[37] A. A. Anwar and D. Clarke, "Irrigation scheduling using mixed-integer linear programming," J. Irrig. Drain. Eng., vol. 127, no. 2, pp. 63-69, 2001.

[38] A. Tafteh, H. Babazadeh, N. A. Ebrahimipak, and F. Kaveh, "Optimization of irrigation water distribution using the mga method and comparison with a linear programming method," Irrig. Drain., vol. 63, no. 5, pp. 590-598, 2014.

[39] A. A. Fasakhodi, S. H. Nouri, and M. Amini, "Water Resources Sustainability and Optimal Cropping Pattern in Farming Systems; A Multi-Objective Fractional Goal Programming Approach,” Water Resour. Manag., vol. 24, no. 15, pp. 4639-4657, 2010 . 
[40] H. Ahmed, "A Proposed Linear Programming Based Algorithm to Solve Arc Routing Problems," Int. J. Math. Sci. Comput., vol. 6, no. 2, pp. 61-70, 2020 .

\section{Authors' Profiles}

Alanoud Alotaibi is a lecturer of Information Systems at the College of Computer and Information Sciences. She is a PhD student in the information systems department at King Abdulaziz University. She obtained her Master's degree in Information Systems from Imam Muhammad bin Saud University and her Bachelor also in Information Systems. Alanoud has published research papers in different Journals. She has been a member of the Academic Advising Committee in the information systems department for more than 8 years. She participated and worked with different committees in the department. Her interests: in decision-making technologies, information systems and object-oriented, database management, and machine learning.

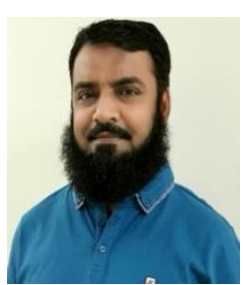

Farrukh Nadeem is a gold medalist in B.Sc. and completed M.Sc. Computer Science from the University of Punjab, Pakistan. He completed his Ph.D. with distinction in computer science in 2009 from the University of Innsbruck, Austria. He is an associate professor at the Faculty of Computing and Information Technology, King Abdulaziz University, Jeddah. He holds several distinctions and awards during his educational career. He has been involved in several Austrian research projects and is working on a couple of Saudi research and development projects. He is a member of the program committees of several conferences and an editorial board member of the Journal of Modern Education and Computer Science. Farrukh has authored more than 29 conference and journal research papers, including four book chapters. He has been awarded the President (King Abdulaziz University) Certificate of Appreciation and cash award for one of his journal publications. His main research interests include performance modeling and prediction, the Internet of Things, and smart healthcare.

How to cite this paper: Alanoud Alotaibi, Farrukh Nadeem, " A Review of Applications of Linear Programming to Optimize Agricultural Solutions", International Journal of Information Engineering and Electronic Business(IJIEEB), Vol.13, No.2, pp. 11-21, 2021. DOI: 10.5815/ijieeb.2021.02.02 